\title{
Aspectos de gestão orçamentária e financeira de unidades de saúde terceirizadas no âmbito do Sistema Único de Saúde - SUS: primeiros resultados
}

Recebido: 28 jan 2019 Aceito: 10 fev 2019

Autor de correspondência: lonardoluzsilva@gmail.com

Conflito de interesses: Os autores declaram não haver nenhum interesse profissional ou pessoal que possa gerar conflito de interesses em relação a este manuscrito.

\author{
Leonardo Luz da SILVA ${ }^{(1)}$ \\ Leonardo CARNUT $^{(1)}$ \\ ${ }^{(1)}$ Faculdade de Saúde Pública, Universidade de São Paulo - USP, São Paulo, SP, Brasil.
}

\section{Resumo}

Em 1995 teve início no Brasil, através da criação do Ministério de Administração e Reforma do Estado - MARE, a Reforma da Gestão Pública ou Reforma Gerencial do Estado com a publicação do Plano Diretor da Reforma do Aparelho de Estado - PDRAE e o posterior envio para o Congresso Nacional da Emenda da Administração Pública que se transformaria na Emenda Constitucional 19/1998. O objetivo da reforma implementada foi o de promover a modernização da administração pública brasileira considerando a nova conjuntura mundial, marcada pela globalização, tornando-a mais eficiente. Havia, nesse sentido, a proposta de mudança da então administração burocrática para a administração gerencial. Segundo Bresser-Pereira (1998), o Estado moderno deveria ser dividido em quatro setores que ajudaria a enxugar a máquina pública destinando-a, apenas, suas funções essenciais: núcleo estratégico, as atividades exclusivas, os serviços não exclusivos e a produção de bens e serviços para o mercado. Na reforma proposta, as atividades não exclusivas (ou competitivas) do Estado, como a saúde e a educação, deixariam de ser executadas diretamente por ele e passariam ao denominado setor público não-estatal, onde figurariam diversas modalidades de gestão das quais as organizações sociais (OS) são uma delas. Embora não representem figura jurídica inédita, pois se inserem na ordem legal vigente sob a forma de associações civis sem fins lucrativos, vale dizer, pessoas jurídicas de direito privado, especialmente as organizações sociais constituem um novo modismo institucional. A novidade seria a qualificação mediante decreto, que habilitaria a entidade assim classificada a receber recursos financeiros e a administrar bens e equipamentos do Estado por meio da assinatura de um contrato de gestão, com metas, indicadores de desempenho etc., que garantem a efetividade dos serviços prestados ao público. É nesta celebração em que o contrato de gestão entre o poder público e as organizações sociais seria, portanto, o elemento fundamental desta proposta e que permitiria a administração gerencial almejada alcançar a prestação dos serviços que, por questões que ultrapassaria a esfera da gestão, não seriam realizados. Assim o contrato, prevê multas, resultados, prestação de contas, processos de fiscalização, modelo de estrutura e outros itens. Estabelecido o novo cenário de contratualização com o setor privado na área da saúde iniciado pelos entes da federação (mesmo que em diferentes momentos) e considerando 
que em questões ligadas à saúde, por não serem previsíveis e pela ausência das condições de perfeita competição, onde o consumidor não é soberano e é vulnerável, entre outras condições, a riscos e incertezas, à distribuição desigual da informação sobre a qualidade da assistência, à existência de barreiras no acesso e às chamadas externalidades, destaca-se a importância de se desenvolver dispositivos e mecanismos de controle e regulação das entidades privadas que passam a operar a assistência à população, vez que o poder público assume crescentemente o papel de regulador, e não mais de executor. Nesse sentido, o presente trabalho tem o objetivo de verificar o que existe na literatura nacional sobre os aspectos de gestão orçamentária e financeira de unidades de saúde terceirizadas no âmbito do Sistema Único de Saúde - SUS. Objetivo: revisar a literatura sobre os aspectos de gestão orçamentária e financeira de unidades de saúde terceirizadas no âmbito do SUS. Método: o presente trabalho é uma revisão da literatura do tipo integrativa dos aspectos de gestão orçamentária e financeira de unidades de saúde terceirizadas no âmbito do SUS, verificando a produção científica disponível através de busca sistematizada realizada no Portal regional da BVS e bases de dados indexadas a este portal. Como estratégia de busca, utilizou-se a técnica de funil, utilizando-se diversos descritores em ciências da saúde, identificados a partir da pergunta de pesquisa que foram agrupados em três diferentes grupos [população (I), contexto (II) e fenômeno (III)], e posterior refinamento da busca através de sintaxes com os operadores booleanos $O R$ e/ou $A N D$. Optou-se, também, pela adição da busca por título utilizando a expressão "inserção privada" de modo a se obter nos resultados, complementarmente, a tese de doutorado de Pahim (2009), não captada pela referida estratégia de busca e que aborda aspectos relevantes da gestão financeira do modelo de Organizações Sociais de Saúde no Estado de São Paulo. Considerações finais: retornou resultados relevantes, principalmente, a busca (I) $A N D$ (II) $A N D$ (III) $O R$ "inserção privada" (título), totalizando 116 estudos identificados, cuja sintaxe final é: (mh:((mh:("servicos terceirizados" $O R$ "servicos contratados" $O R$ "organizacao social" $O R$ "privatizacao" $O R$ "instalacoes de saude" $O R$ "servicos de saude" $O R$ "hospitais públicos")) $A N D$ (mh:("sistema unico de saude")) $A N D$ (mh:("custos e analise de custo" $O R$ "custos diretos de servicos" $O R$ "avaliacao em saude" $O R$ "gastos em saude" $O R$ "gestao em saude" $O R$ "controle de custos" $O R$ "Eficiência" $O R$ "Eficiência Organizacional" $O R$ "orcamentos" $O R$ "Recursos Financeiros em Saúde")))) $O R$ (ti:("inserção privada")). Em análise preliminar, observam-se que poucos artigos publicados abordam, de fato, os aspectos de gestão orçamentária e financeira de unidades de saúde que foram terceirizadas no âmbito do SUS e que os trabalhos que mais se aprofundam na temática são teses apresentadas em programas de pósgraduação.

Descritores: Organização Social; Serviços Terceirizados; Gastos em Saúde; Gestão em Saúde; Orçamentos; Recursos Financeiros em Saúde; Sistema Único de Saúde. 